DOI: $10.33910 / 1992-6464-2020-198-45-55$

И. А. Макеева

\author{
СОЦИАЛЬНАЯ ЭКСКЛЮЗИЯ И ИНКЛЮЗИЯ \\ В КОНТЕКСТЕ ОБРАЗОВАНИЯ: СУЩНОСТЬ, ПОДХОДЫ
}

\begin{abstract}
В статье представлен анализ категорий «сочиальная эксклюзия» и «сочиальная инклюзия» применительно к сфере образования, показана взаимообусловленность данных процессов, соотношение с прочессами депривачии, отчуждения, интеграции. Раскрыты факторы сочиальной эксклюзии, проблема самоэксклюзии, определены актуальные группы детей-жертв эксклюзии, охарактеризовано инклюзивное образование как инструмент соииальной инклюзии. Продемонстрировано соотношение социальной и образовательной инклюзии как общего и частного, но при этом базирующихся на общих основаниях - осознании иенности человеческого многообразия, необходимости социального взаимодействия на основе сотрудничества, уважения, принятия.
\end{abstract}

Ключевые слова: социальная эксклюзия, социальная инклюзия, инклюзивное образование, депривация, интеграция, жертвы эксклюзии, самоэксклюзия.

I. Makeeva

\title{
SOCIAL EXCLUSION AND INCLUSION IN THE CONTEXT OF EDUCATION: ESSENCE, APPROACHES
}

The article presents an analysis of the categories "social exclusion" and "social inclusion" in the field of education, shows the mutual condition of these processes, the relationship with the processes of deprivation, exclusion, integration. The factors of social exclusion, the problem of selfexclusion are revealed, groups of children at risk of being a victim of exclusion are identified, inclusive education is characterized as an instrument of social inclusion.The relationship between social and educational inclusion is demonstrated as the relationship between the general and the particular, but based on common grounds - the awareness of the value of human diversity, the need for social interaction based on cooperation, respect, and acceptance.

Keywords: social exclusion, social inclusion, inclusive education, deprivation, integration, victims of exclusion, self-exclusion.

Сложность современного периода в развитии нашего общества, масштабность и острота его социальных, культурных и экономических проблем обуславливают актуальность поиска оптимальных путей расширения сфер социальной инклюзии, снижения рисков социального исключения, особенно социально уязвимых групп. Образование является одной из тех сфер жизни общества, в которой реализация инклюзивных процессов имеет стратегическое значение, поскольку именно в процессе образова- ния формируются ценностные установки, модели поведения, позволяющие на практике реализовывать инклюзивные идеи. Следует отметить, что социальная инклюзия гораздо шире образовательной инклюзии, и инклюзивное образование является ее инструментом.

Для всестороннего осмысления феномена социальной эксклюзии/инклюзии, преодоления возможной неопределенности в интерпретации смыслов сопряженных понятий (таких как депривация, стигматизация, 
интеграция и др.) целесообразно систематизировать категориально-понятийное поле применительно к образовательной сфере.

Рассмотрение категорий «социальная инклюзия» и «социальная эксклюзия» в неразрывном единстве принципиально важно именно в аспекте образования, поскольку его целью является преодоление (максимальное снижение) рисков негативной социализации и, как следствие, социального исключения детей и подростков. Причем в поле зрения социальной инклюзии включены не только дети с ОВЗ и с инвалидностью, но и ряд других групп детей - дети-мигранты, дети-сироты, дети из неблагополучных семей и т. д. Теоретический анализ понятий «социальная эксклюзия» и «социальная инклюзия» имеет целью обоснование их смысловой и содержательной самостоятельности, с одной стороны, и взаимообусловенности - с другой, а также выработку адекватных мер поддержки обучающихся и инклюзивных методик.

В общем плане можно выделить ряд этапов в развитии научных представлений о сущности понятия «социальное исключение» (эксклюзия).

Первый этап - 60-е гг. XX века. Термин «социальное исключение» применялся для характеристики людей маргинальной направленности, которые оказались вне экономической системы главным образом в силу своих личностных особенностей, таких как «безответственность и непредусмотрительность». В данном подходе также акцентируется внимание на проблеме социального неравенства, которое порождает социальных изгоев, т. к. им недоступны ресурсы, необходимые для нормального существования.

Второй этап - 70-е гг. XX века. На данном этапе происходит смещение в оценке социального исключения, которое теперь рассматривается прежде всего как общественный феномен, являющийся следствием функционирования общества (рост урбанизации, стандартизация образования, дифференцированность доходов населения, ограниченный доступ к социальным ресурсам). Важно отметить, что в исследованиях этого периода отмечается тенденция к социальной исключенности не только типичных, маргинальных групп населения (правонарушителей, людей с зависимостями, мигрантов), но и социально благополучных категорий, которые в силу обстоятельств тоже могут стать жертвами эксклюзии.

Третий этап - 80-90-е гг. XX века. В исследованиях наблюдается замена термина «социальное исключение» на термин «нестабильная ситуация», которая соотносилась преимущественно с нестабильностью на рынке труда, увеличением безработных и объективной возможностью вполне благополучных людей, социально и материально стабильных стать исключенными. В данный период социальное исключение рассматривается как следствие разрыва привычных социальных связей и ограничения доступа к необходимым жизненным ресурсам.

Следует подчеркнуть, что в исследованиях конца XX в. термин «социальная эксклюзия» в большей степени фиксирует растущую неустойчивость социальных связей (нестабильность семьи, рост числа одиноко живущих людей, социальную изоляцию отдельных категорий), что требует активизации в проведении профилактической и коррекционной работы.

По мнению Ч. Гора, термин «социальное исключение» (эксклюзия) был введен Р. Ленуаром в 1974 году для характеристики социальной ситуации, в которой оказались определенные категории людей, относящихся к социально незащищенным группам, таким как сироты, инвалиды, склонные к суициду, безработные, бездомные и т. д. [20].

В зарубежных и отечественных исследованиях рассматривается вопрос о масштабах социальной эксклюзии (R. Atkinson, F. Farrington, P. Stroebel, M. С. Астоянц и др.) $[1 ; 16 ; 18 ; 23]$. В работах Н. В. Тихоновой социальная эксклюзия рассматривается в контексте явлений депривации и дискри- 
минации [10]. В аспекте социализации личности проблема социальной исключенности представлена в исследованиях Н. В. Зубаревич, В. И. Ильина [5; 6]. В целом проблемы образовательной инклюзии рассматриваются в работах А. В. Бахарева, Э. Е. Жилкиной, Т. В. Фуряевой $[2 ; 4 ; 12]$.

Наиболее распространенным в зарубежных научных исследованиях является понимание социальной эксклюзии как феномена, обозначающего явление социального неблагополучия, ограничения или отсутствия доступа к необходимым и достаточным ресурсам, выпадения человека из общественных структур, смещение на «социальное дно» (P. Abrahamson, S. Paugam, A. Power, W. J. Wilson) [15;21;22]. Подобную трактовку социальной эксклюзии можно рассматривать применительно к процессу социализации личности. Точками пересечения можно считать, с одной стороны, необходимость войти в общество (социализация) и невозможность или ограниченная возможность сделать это (эксклюзия); с другой стороны, качество факторов социализации (необходимые и достаточные ресурсы) - семейное окружение, образование, поддержка, и ограниченность этих ресурсов - неблагополучная семья / отсутствие семьи, недостаточность социально-педагогической поддержки и т. д. По мнению А. Гидденса, социальная эксклюзия является механизмом, «отдаляющим некоторые группы людей от главного социального потока», то есть фактором риска, неблагополучия, причиной и следствием неуспешной девиантной социализации $[19$, c. 97$]$.

В зарубежных и отечественных исследованиях также дискутируется вопрос о масштабах социальной эксклюзии. П. Строебел (P. Stroebel) подчеркивает, что нарушается только одна подсистема [21]. Р. Аткинсон, Ф. Фаррингтон (R. Atkinson, F. Farrington) считают, что происходит своеобразная ломка нескольких систем, поэтому социальное исключение можно охарактеризовать как цепную реакцию $[14 ; 18]$. Второй подход более близок образованию, поскольку ребенок является частью нескольких социальнокоммуникативных систем: семья, школа, группа сверстников, среда, социальные сети, этническая группа т. д. Нарушение в одной системе, например, воспитание в неблагополучной семье, отсутствие семьи, наличие инвалидности, миграция, приводят к нарушениям в других, в частности, в образовании - снижению успеваемости, подверженности буллингу, девиации. В результате нарушается механизм социализации, гражданского становления. Следовательно, данный подход подтверждает необходимость учета многоаспектности «образовательных» проблем ребенка, причины которых могут корениться в семье, состоянии здоровья, коммуникации и т. д., и соответственно, необходимости комплексности в их решении, реализации командной стратегии.

Определения понятия «социальная эксклюзия» тесно переплетаются с понятиями «депривация» и «дискриминация». Характеристика социальной инклюзии в широком смысле слова сосредоточивается на отсутствии доступа к механизмам интеграции. В данном контексте основным выступает понятие «дискриминация». Характеристика социальной инклюзии в узком смысле, на микроуровне, предполагает анализ положения носителей социальной эксклюзии и сосредоточивается на том, в чем проявляется специфика жизненной ситуации членов этой группы по отношению к другим членам общества. Соответственно, на первый план выходит понятие «депривация».

Отметим, что термин «депривация» следует рассматривать двояко: во-первых, для обозначения реального ограничения (лишения, утраты) условий жизни и функционирования, которые необходимы для нормального развития и сохранения психических функций (потеря семьи, места жительства, здоровья), и во-вторых, для обозначения психического состояния, поведения, возникающего в результате подобных ограничений (суицидальные проявления, девиации, 
аддикции). Соответственно, депривацию можно рассматривать как причину социальной эксклюзии - отсутствие или ограничение доступа к ресурсам, необходимым для полноценного развития и социализации ребенка и, как следствие - утрата возможности и способности преодолевать ограничения, активизировать и использовать личностный потенциал или реализация его в диссоциальном контексте (аддиктивное, делинкветное поведение).

Важным аспектом образования является социально-педагогическая деятельность в сфере социализации - социального становления человека. Практики социального исключения осуществляются как на индивидуальном уровне, в процессе социализации, так и на общесоциальном, на уровне общества в целом. Исключением на индивидуальном уровне называют нарушение правильной социализации, выталкивание, выход за пределы нормального сообщества, приводящие к негативным последствиям. Следовательно, успешная (позитивная) социализация предполагает включение человека в общество, неуспешная (виктимная) социализация - исключение. В контексте социализации характеристика социальной эксклюзии может рассматриваться в рамках социальной виктимологии, которая оперирует такими понятиями, как «процесс виктимизации», «факторы виктимизации», «жертва неблагоприятных условий социализации», которые синонимичны таким понятиям, как «эксклюзия», «факторы (причины) эксклюзии», «жертва эксклюзии».

Факторы (причины) социальной эксклюзии (виктимизации) многочисленны и многоаспектны, понимаются как обстоятельства, переводящие индивида или группу из нормального состояния в состояние социального исключения, т. е. обстоятельства, приводящие к социальному неблагополучию, формированию трудной жизненной ситуации. Они могут иметь объективный (действуют извне) и субъективный характер (зависят от человека, обусловлены его личностными и индивидными особенностями). Влияние объективных факторов эксклюзии велико, и их преодоление (устранение) может быть затруднено или невозможно. Наиболее значимыми факторами социальной эксклюзии для детей и подростков считаем семейное неблагополучие, низкий материальный уровень (бедность) семей (особенно многодетных), ограниченность (неразвитость) социальной инфраструктуры для детей и низкий уровень ее физической и материальной доступности. Солидарны с мнением Н. В. Зубаревич, В. И. Ильина в том, что России присущ феномен «глубинки», которая занимает основную территорию страны и является «исключенной» территорией, т. к. изолирована от центров социального благополучия плохими дорогами, плохой связью, недостатком информационных ресурсов, и поэтому многие сельские семьи живут в ситуации социальной эксклюзии в том отношении, что не могут пользоваться возможностями рынка труда, правом на медицинскую, социальную помощь, качественным образованием по месту проживания, не имеют доступа к культурным благам [5; 6].

Следует отметить, что социальное исключение может быть полным или частичным, но в любом случае приводит к ослаблению и разрыву социальных связей, за которым следуют кризис личностной идентичности и социальная дисквалификация человека. Важно понимать, что исключение ребенка из активной социальной жизни вызывает в нем отчуждение, которое является причиной многих видов девиантного поведения, так как приводит к замене легитимных форм социального взаимодействия, доступ к которым оказался для него закрытым, к девиантным формам. По мнению Т. В. Шипуновой, термин «отчуждение» используется в научной литературе преимущественно для обозначения отстранения индивида или социальной группы от каких-либо материальных или духовных благ, ресурсов, возможностей. И в таком контексте понимание отчуждения совпадает с социальным исключением. 
Однако следует отметить, что понятие «отчуждение» шире, поскольку включает в себя также характеристику состояния человека, в отношении которого совершается такое отстранение [13].

Следовательно, отчуждение можно трактовать как объективный социальный процесс, ограничивающий возможности человека, с одной стороны, и как психологическое состояние человека, характеризующее его негативное отношение к окружающей действительности, с другой. Таким образом, в аспекте образования рассматриваем отчуждение как мироощущение и умонастроение ребенка, при которых он воспринимает окружающую действительность как несправедливую, чуждую и враждебную ему и которые являются психологическим (субъективным) следствием объективной лишенности ребенка возможности контролировать условия собственной жизни. На практике специалисты часто сталкиваются с тем, что семья игнорирует существующую проблему, не видит необходимости в изменении жизненной ситуации или перекладывает ответственность за решение проблемы на школу, самоустраняется. Этот процесс может быть по преимуществу психологическим - направленным от внутреннего состояния индивида к формированию ситуации, которую можно назвать самоэксклюзией. Ситуация самоэксклюзии наблюдается, например, при отказе от активного решения проблемы по возвращению ребенка в случае лишения родительских прав, преодоления семейного неблагополучия, конфликтных отношений с ребенком, нежелания идти на контакт, взаимодействовать с педагогами или перекладывании на школу решения проблемы.

Немаловажно и то, каким образом личность предрасположена реагировать на невозможность реализации наиболее значимых для нее потребностей. От этого зависит ее способность преобразовывать свой внутренний мир, переосмысливать свое существование, обрести благодаря переоценке ценно- стей смысл существования в изменившихся условиях.

Следовательно, состояние социальной эксклюзии определяется индивидуальным восприятием ситуации и самоидентификацией. Например, одни дети-сироты и дети с инвалидностью считают себя жертвами, что и определяет их самоотношение и поведение, другие - нет. Многие из них, наоборот, проявляют такую высокую физическую и общественную активность, которая не свойственна «обычным» детям.

В контексте рассматриваемой проблемы необходимо определение групп, категорий детей - социально уязвимых, социально незащищенных, групп риска и т. д., которые могут конституироваться как жертвы социальной эксклюзии.

В Федеральном законе «Об основных гарантиях прав ребенка в Российской Федерации» в статье 1 выделены следующие группы: дети, находящиеся в трудной жизненной ситуации, дети, оставшиеся без попечения родителей; дети-инвалиды; дети с ограниченными возможностями здоровья, то есть имеющие недостатки в физическом и (или) психическом развитии; дети - жертвы вооруженных и межнациональных конфликтов, экологических и техногенных катастроф, стихийных бедствий; дети из семей беженцев и вынужденных переселенцев; дети, оказавшиеся в экстремальных условиях; дети жертвы насилия; дети, отбывающие наказание в виде лишения свободы в воспитательных колониях; дети, находящиеся в образовательных организациях для обучающихся с девиантным (общественно опасным) поведением, нуждающихся в особых условиях воспитания, обучения и требующих специального педагогического подхода (специальных учебно-воспитательных учреждениях открытого и закрытого типа); дети, проживающие в малоимущих семьях; дети с отклонениями в поведении [11]. Важно, что в данной статье зафиксированы не только жертвы социальной эксклюзии и одновременно объекты социальной инклюзии, 
но и охарактеризованы причины исключения детей, что необходимо для специалистов сферы образования в аспекте планирования и осуществления профилактической и коррекционной работы.

Кроме того, необходимо учитывать, что названные категории жертв социальной эксклюзии далеко не всегда представляются в «чистом виде»: часто первичные дефекты, отклонения от нормы или какие-то объективные жизненные обстоятельства (неблагополучная семья) вызывают вторичные изменения в развитии человека, формируют неадекватные или ущербные отношения к миру и к себе.

Следует отметить, что в нормативноправовых актах отражены категории детей, которые традиционно являются объектами помощи и внимания. Однако практика свидетельствует о необходимости расширения и уточнения эксклюзированных категорий детей. В современных условиях к таким категориям считаем необходимым отнести: детей с ОВ3 и с инвалидностью (поскольку доступность инклюзивного образования недостаточна для получения качественного образования и обеспечения необходимого сопровождения ребенка и семьи); ВИЧ-положительных детей и подростков (поскольку высок риск стигматизации и дискриминации); детей из малообеспеченных семей (поскольку ограничена/отсутствует доступность необходимых ресурсов); детей из социально неблагополучных семей (поскольку процессы социального исключения имеют комплексный и часто необратимый характер); детей-сирот и детей, оставшихся без попечения родителей, проживающих в центрах помощи детям-сиротам (поскольку большая их часть — это подростки, которые или не имеют опыта семейного воспитания вообще, или имеют негативный опыт воспитания в кровной семье, или были возвращены приемными родителями); детей, оставшихся без попечения родителей, проживающих в приемных семьях (поскольку существует риск возврата, повторного отказа); детей-инофонов (поскольку существует риск школьной дезадаптации); детей и подростков с аддиктивным поведением (поскольку спектр аддикций постоянно расширяется - селфи-зависимость, вовлеченность в суицидальные интернет-сообщества и др.); подростков, относящихся к ЛГБТ-сообществу, - лесбиянок, геев, бисексуалов, трансгендеров (поскольку высок уровень нетерпимости в обществе и риск стигматизации и дискриминации, соответственно); жертв буллинга (поскольку травля приводит не только к психологической и физической травматизации жертвы, но и негативным последствиям для инициатора буллинга).

Таким образом, проанализировав различные подходы к пониманию социальной эксклюзии, в аспекте образования определяем социальную эксклюзию как процесс исключения отдельных детей и семей, а также групп из системы социальных отношений, ограничения доступа к необходимым ресурсам, невозможности реализации прав (в том числе права на образование), что приводит к социальному неблагополучию, ущемленности, ухудшению условий жизнедеятельности, т. е. к возникновению трудной жизненной ситуации. Следовательно, для образования важно рассмотрение социальной эксклюзии с позиции определения причин возникновения социального исключения, возможных последствий для их профилактики и коррекции, и конституирования объектов социально-педагогической, психологопедагогической помощи.

Социальная инклюзия является обратной стороной социальной эксклюзии и в общем виде может пониматься как включение человека в общество, активное взаимодействие, функционирование в определенной социальной роли. В данном аспекте инклюзивное образование выступает в качестве ведущего инструмента реализации принципов социальной инклюзии.

Для теории и практики инклюзивного образования наиболее актуальным является вопрос о соотношении процессов интеграции 
и инклюзии, проблема концептуализации категорий социальной инклюзии и интеграции, так как это важно для определения целей и задач инклюзивного образования, его миссии в обществе.

Обобщение имеющихся исследований по данному вопросу позволяет выделить два основных подхода.

В рамках первого подхода интеграция рассматривается двояко: с одной стороны, как процесс адаптации человека к окружающей среде; с другой - как процесс сохранения стабильного функционирования системы при включении в нее новых элементов. Интеграция является одновременно целью и результатом социальной инклюзии, инклюзия - лишь инструмент. Следовательно, социальная инклюзия рассматривается как более частное, узкое понятие относительно социальной интеграции.

По мнению Г. Эндрувайта, интеграция представляет собой процесс включения в систему новых элементов, в результате которого новые элементы ничем не отличаются от прежних элементов этой системы [17]. Следовательно, новые элементы должны приспособиться к особенностям системы, приобрести общие характеристики, как бы «слиться с ней», потеряв при этом часть своей индивидуальности, идентичности. Схожая позиция у М. С. Астоянц и И. Г. Россихиной, которые, сравнивая процессы инклюзии и интеграции, приходят к выводу, что «интеграция есть процесс включения в систему новых элементов». Следовательно, интеграция может рассматриваться как результат социальной инклюзии, которая выступает ее механизмом [1].

Ряд исследователей (Р. Дименштейн, И. Ларикова) считают, что интеграция - это результат инклюзии, но они акцентируют внимание на том, что процессы инклюзии и интеграции разворачиваются на разных уровнях: интеграция - на микро- и мезоуровнях - это отдельные люди и группы, а инклюзия - на макроуровне, т. к. затрагивает все институты и сферы общества [3].
По мнению Э. И. Леонгард, интеграция схожа с процессом ассимиляции, т. к. требует принятия человеком норм, ценностей, моделей, присущих традиционной культуре и выстраиванию своего социального поведения в соответствии с ними [8]. Анализ соотношения процессов интеграции и инклюзии показывает, что интеграция предполагает «готовность» ребенка (человека) к принятию его дошкольным учреждением, школой и обществом, т. е. он должен «подойти», адаптироваться к определенным условиям, ситуациям, системе, а не наоборот. Данная позиция определяет ответственным за свое включение самого человека - насколько он будет успешным или нет, зависит от него, его потенциала, возможностей. Инклюзия же подразумевает адаптацию, готовность школы, среды, общества к принятию особенного человека или просто другого, с которым данная система еще не сталкивалась. Но тем не менее именно она берет на себя ответственность за создание необходимых условий, «принимающей среды», способной адекватно отреагировать на возможности, способности, ограничения человека, в том числе и социальные.

В рамках второго подхода «инклюзия больше, чем интеграция», т. к. интеграция предполагает адаптацию человека к требованиям системы, тогда как инклюзия заключается в адаптации системы к потребностям человека. Согласно международным канонам, инклюзия в своих основных постулатах опирается на принцип адаптации системы к индивидуальным потребностям человека.

Е. Р. Ярская-Смирнова рассматривает социальную инклюзию как «демократическую акцию, благодаря которой индивид или группа включаются в широкое общество и приобщаются к определенному действию, культурному процессу» $[14$, с. 136]. Реализация идей инклюзии способствует преодолению неравенства, созданию условий для реализации человеческого потенциала, обеспечения нового качества жизни. Можно сказать, что в качестве основополагающих категорий 
социальной инклюзии выступают, прежде всего, такие, как уважение, принятие, самореализация, общечеловеческие ценности (общение, привязанность, дружба, сопереживание и др.).

Политика инклюзии декларирует необходимость изменения общества и его институтов таким образом, чтобы они способствовали включению любого человека (другой расы, вероисповедания, культуры, человека с OB3 и др.). При этом важно, чтобы это включение содействовало интересам всех членов общества, обеспечению равенства их прав и т. д. Научный анализ категорий «инклюзия» и «интеграция» позволяет утверждать, что интеграция отличается попыткой «возвратить», например, лиц с ОВ3 в общество, то есть снизить риск сегрегации, эксклюзии. Определяющей же идеей инклюзии является признание для общества равной ценности всех людей, независимо от их способностей и возможностей.

В социальном аспекте идеология инклюзии исходит из идеи о том, что различие между людьми, какими бы причинами оно ни определялось, рассматривается как естественное явление и не может служить основанием для ограничения их прав. Инклюзия направлена на увеличение степени участия всех без исключения людей в социальных процессах, т. е. формирование гетерогенного общества, которое принимает разнообразие и многообразие как объективную реальность. Следовательно, в аспекте инклюзивного образования разнообразие, различия между учениками необходимо рассматривать не как проблему, а как ресурс развития детского коллектива и общества в целом, актуализация которого приводит к позитивным изменениям не только непосредственно объектов инклюзии, но и всех субъектов, включенных в социальное взаимодействие.

Позиция сохранения своеобразия каждого участника жизненной общности как основы социальной инклюзии получила развитие в контексте педагогики разнообразия, педагогики гетерогенности, в рамках которой считается, что ценность каждого участника общности не зависит от его способностей и дефицитов, так как каждый человек вносит свой неповторимый, уникальный вклад в общее дело, в общее бытие. Инклюзивная интеграция ориентирует на стимулирование разнообразных процессов совместной жизни, позволяющей каждому «вписаться» со своим своеобразием. Каждый индивид стремится к самоопределению, нахождению своей области жизни, сферы деятельности.

С позиции современных тенденций развития системы образования отметим, что второй подход к пониманию соотношения процессов инклюзии и интеграции наиболее точно отражает сущность и назначение института образования в обществе как инструмента его гуманизации, создания условий для включения каждого человека в систему социальных отношений на разных уровнях, принятия его как компонента людского многообразия, признания и реализации его права быть собой.

Как отмечалось выше, важным инструментом социальной инклюзии является инклюзивное образование. Согласно «Конвенции ООН о правах инвалидов» (2006), инклюзивное образование как основное направление обеспечения права на образование для лиц с инвалидностью должно стать законодательно закрепленным институтом, имеющим все необходимые компоненты, начиная от выделения соответствующего финансирования, определения механизмов создания специальных условий и принципов адаптации образовательной среды в отношении детей, имеющих разнообразные образовательные потребности до обеспечения комплексного сопровождения ребенка и семьи, а также методической поддержки педагогов [7]. В Конвенции подчеркивается антидискриминационный, развивающий и личностноориентированный, гуманистический характер инклюзивного образования, его направленность на социальное развитие человека с инвалидностью. 
Инклюзивное образование понимается как образование, целью которого является полное развитие человеческого потенциала, необходимого для эффективного участия в жизни общества наравне со всеми. При реализации права на образование необходимо гарантировать равный доступ детейинвалидов к качественному образованию в местах своего проживания; обеспечить разумное приспособление среды, учитывающее их индивидуальные потребности. Следовательно, необходимо обеспечить инклюзивную вертикаль образования для лиц с инвалидностью на всех уровнях, адаптацию образовательной среды, что предполагает приспособление физической среды (доступность), подготовку педагогов, изменение системы оказания индивидуальной и дополнительной поддержки, предоставление ученикам возможности обучаться по индивидуальным учебным планам, изменение принципов и процедуры оценки и аттестации обучающихся.

Важным условием реализации на практике инклюзивной модели образования является правовое регламентирование организационно-методических аспектов - возможности получения профессиональной поддержки (тьюторского сопровождения) в процессе получения образования. Так, Конвенцией о правах инвалидов закрепляется право обучающихся с ОВ3 на получение требуемой индивидуализированной поддержки внутри системы общего образования [7]. Согласно «Саламанкской декларации о принципах, политике и практической деятельности в сфере образования лиц с особыми потребностями», необходимо создавать условия (организационные, методические, технологические), которые позволят обеспечить качественную реализацию инклюзивной модели образования [9].

Следовательно, реализация модели инклюзивного образования, согласно положениям международного права, гарантирует каждому ребенку реализацию одного из основных прав - права на образование, признавая при этом уникальные особенности, интересы, способности и учебные потребности всех детей. Детям с ограниченными возможностями здоровья должна быть обеспечена максимальная доступность образовательного учреждения, близость к месту проживания, необходимые условия (безбарьерная среда вне и внутри образовательной организации) для совместного обучения со здоровыми сверстниками.

Таким образом, обобщая все вышесказанное, определяем социальную эксклюзию как многомерный кумулятивный процесс, нарушающий социальные связи индивидов или групп и препятствующий их участию в жизни общества, и состояние отверженности человека, возникающее вследствие этого процесса. Социальная инклюзия, наоборот, означает полное участие всех членов сообщества в его жизнедеятельности и имеет ряд аспектов: политико-правовой (возможность реализации своих прав и интересов), социально-экономический (преодоление бедности, повышение уровня и качества жизни), социокультурный (доступное и качественное образование, включенность в культурную, спортивную жизнь), психологический (толерантность, позитивная самоидентификация, чувство принадлежности к сообществу) и др.

Сравнительный анализ понятий эксклюзии и инклюзии показывает, что они могут рассматриваться только во взаимосвязи, поскольку понимание причин (факторов) социального исключения помогает прогнозировать развитие ситуации, разрабатывать меры профилактики и преодоления последствий социального исключения, в том числе и в сфере образования.

Следует также отметить, что образование в контексте инклюзивного подхода следует рассматривать, выходя за рамки чисто образовательного процесса, поскольку образование является инструментом социальной инклюзии в широком смысле. Помимо детей с инвалидностью и ОВ3, объектами социальной инклюзии могут быть дети-инофоны, дети из семей мигрантов, 
дети-сироты, дети из социально неблагополучных семей и т. д., которые, получая социально-педагогическую и психолого-педагогическую поддержку в школе, могут успешно социализироваться, тем самым снизить риски социального исключения.
Социальная инклюзия в образовании базируется на осознании ценности человеческого многообразия, необходимости социального взаимодействия на основе сотрудничества, уважения, принятия, понимания.

\section{СПИСОК ЛИТЕРАТУРЫ}

1. Астояни М. С., Россихина И. Г. Социальная инклюзия: попытка концептуализации и операционализации понятия // Известия Южного федерального университета. Педагогические науки. 2009. № 2. C. $51-58$.

2. Бахарев А. В. Развитие инклюзивных практик в истории современного российского образования: автореф. дис. ... канд. пед. наук. М., 2018. 23 с.

3. Дименштейн Р., Ларикова И. Интеграция или инклюзия? Спор о словах и нерешенных проблемах образования «особых» детей // Защити меня. 2008. № 1. С. 55-59.

4. Жилкина Э. Е. Проблемы и перспективы развития инклюзивного образования в России на современном этапе // Инклюзия в образовании. 2016. № 3 (3). С. 16-22.

5. Зубаревич Н. В. Регионы России: неравенство, кризис, модернизация. М.: Независимый институт социальной политики, 2010. 160 с.

6. Ильин В. И. Российская глубинка в социальной структуре России // Журнал социологии и социальной антропологии. 2010. Т. ХІІІ. № 4. С. 25-47.

7. Конвенция ООН о правах инвалидов. Принята резолюцией 61/106 Генеральной Ассамблеи от 13 декабря 2006 года. [Электронный ресурc]. URL: https://www.un.org/ru/documents/decl_conv/conventions/ disability.shtml (дата обращения: 31.10.2020).

8. Леонгард Э. И. Инклюзивное образование в различных условиях интеграции // Инклюзивное образование. Выпуск 1 / отв. ред. Т. Н. Гусева. М.: Центр «Школьная книга», 2010. С. 139-148.

9. Саламанкская декларация о принципах, политике и практической деятельности в сфере образования лиц с особыми потребностями. [Электронный ресурс]. URL: https://www.un.org/ru/documents/decl_conv/declarations/pdf/salamanka.pdf (дата обращения: 31.10.2020).

10. Тихонова H. Е. Социальная эксклюзия в российском обществе // Общественные науки и современность. 2002. № 4. С. 5-17.

11.Федеральный закон «Об основных гарантиях прав ребенка в Российской Федерации» № 124-Ф3 от 24 июля 1998 г. [Электронный ресурс]. URL: http://www.consultant.ru/document/cons_doc_LAW_19558 (дата обращения: 31.10.2020).

12. Фуряева T. В. Социальная инклюзия: теория и практика. Красноярск: Красноярский государственный педагогический университет им. В. П. Астафьева, 2019. 280 с.

13. Шипунова T. B. Социальное исключение, отчуждение, насилие и агрессия как механизмы воспроизводства девиантности // Журнал социологии и социальной антропологии. 2005. Т. 8. № 4. С. 120-135.

14. Ярская В. Н., Ярская-Смирнова Е. Р. Инклюзивная культура социальных сервисов // Социологические исследования. 2015. № 12. С. 133-140.

15. Abrahamson P. Postmodern governing of social exclusion: Social integration or risk management // Sociologisk Rapportserie. 1998. No. 13. PP. 77-83.

16. Atkinson R. Combating social exclusion in Europe: The new urban policy challenge // Urban Studies. 2000. Vol. 37. No. 5-6. P. 1037-1055.

17. Endruweit G. Elite und Entwicklung: Theorie und Empirie zum Einfluss von Entwicklungsprozesse. Frankfurt-amMain; Bern; New-York: Peter Lang GmbH, Internationaler Verlag der Wissenschaften, 1986. 502 p.

18. Farrington F. Towards a useful definition: Advantages and criticisms of «Social Exclusion» // Geo View. [Online]. URL: https://www.researchgate.net/profile/fletcher_farrington2/publication/242513425_towards_a_useful_definition_advantages_and_criticisms_of_social_exclusion/links/5b7b363c92851c1e1223ba4 $\overline{\mathrm{d}} / \mathrm{towards}-\mathrm{a}-\mathrm{use}$ ful-definition-advantages-and-criticisms-of-social-exclusion.pdf (accessed 31.10.2020).

19. Giddens A. The class structure of the advanced societies. London: Hutchinson university library, 1973. $366 \mathrm{p}$. 
20. Gore Ch. Introduction: Markets, citizenship and social exclusion // Social Exclusion: Rhetoric Reality Responses / ed. by G. Rodgers, Ch. Gore, J. Figueiredo. Geneva: International Institute for Labour Studies, 1995. P. $1-40$.

21. Paugam $S$. Elements of a comparative research perspective on poverty in European societies. London: Macmillan, 1996. 231 p.

22. Power A., Wilson W. J. Social Exclusion and the Future of Cities. London: Centre for Analysis of Social Exclusion, London School of Economics and Political Science, 2000. 125 p.

23. Stroebel P. From poverty to exclusion: A wage-earning society or a society of human rights? // International Social Science Journal. 1996. Vol. 71. No. 1. P. 5-20. 